\title{
Pengembangan Sistem Ground Control Station Berbasis Internet Webserver pada Pesawat Tanpa Awak
}

\author{
Fredy Aga Nugroho* ${ }^{1}$, Raden Sumiharto ${ }^{2}$, Roghib Muhammad Hujja ${ }^{3}$ \\ ${ }^{1}$ Program Studi Elektronika dan Instrumentasi, FMIPA UGM, Yogyakarta \\ ${ }^{2,3}$ Departemen Ilmu Komputer dan Elektronika, FMIPA UGM, Yogyakarta \\ e-mail: *1 $^{1}$ fredy.aga.n@mail.ugm.ac.id, ${ }^{2}$ r sumiharto@ugm.ac.id, ${ }^{3}$ roghib.muh@ugm.ac.id
}

\begin{abstract}
Abstrak
Dalam operasional pesawat tanpa awak, tugas ground control station sebagai stasiun pemantauan dan komando sehingga operator di darat dapat mengirimkan perintah misi, mengawasi jalannya misi tersebut dan memantau kondisi UAV selama misi berlangsung. Sehingga diperlukan sistem GCS yang mampu terhubung dengan UAV tanpa terbatas dengan jangkauan pemancar kendali.

Penelitian ini mengembangkan sistem GCS menggunakan jaringan internet dan berbasis web server. sistem terdiri dari dua unit, yaitu unit terbang dan unit GCS. Unit terbang terdiri dari Raspberry pi, modem, webcam, modul ADAHRS dan quadrotor dengan controller MultiWii. pada unit GCS terdiri dari Raspberry pi yang tersambung pada jaringan internet dengan kecepatan download 10Mbps dan upload 1.5Mbps.

Sistem GCS ini dapat menampilakan kondisi pesawat, video streaming dan melakukan perintah kendali. Konfigurasi video streaming dengan resolusi $240 x 144$ pixel, bitrate maksimal $256 k b p s$ dan framerate 5 fps menghasilkan delay time tidak lebih dari satu detik. Konfigurasi ini berjalan pada kecepatan upload 1.1 Mbps dengan prosentase kompresi bitrate $93.83 \%$. Data kondisi pesawat yang dikirim ke GCS optimal apabila bandwidth internet melebihi bitrate video streaming yang digunakan pada sistem.
\end{abstract}

Kata kunci-UAV, GCS, Raspberry Pi, Video streaming, FFMPEG, Web Server

\begin{abstract}
In unmanned aerial operations, the ground control station duties as a monitoring and command station so that operators on land can send mission orders, monitor the mission's course and monitor the condition of the UAV during the mission. It is necessary to have a GCS system capable of connecting with UAV that not limited with control transmitter range.

This research develops GCS system using internet network and web server based. the system consists of two units, namely flying units and GCS units. The flying unit consists of Raspberry pi, modem, webcam, ADAHRS module and quadrotor with MultiWii controller. on the GCS unit consists of Raspberry pi connected on the internet network with 10Mbps download speed and 1.5Mbps upload.

The GCS system can display aircraft conditions, stream video and perform command controls. Configure streaming video for delay time of no more than one second with 240x144 pixel resolution, 256kbps maximum bitrate and 5 fps framerate. This configuration runs at a 1.1 Mbps upload speed with a percentage of $93.83 \%$ bitrate compression. Aircraft condition data sent to GCS is optimal if internet bandwidth exceeds the bitrate of streaming video used on the system
\end{abstract}

Keywords-UAV, GCS, Raspberry Pi, Video streaming, FFMPEG, Web Server

Received November $1^{\text {st }}, 2017$; Revised January $3^{\text {rd }}$, 2018; Accepted April 29 ${ }^{\text {th }}, 2018$ 


\section{PENDAHULUAN}

$D^{a}$ alam Beberapa tahun terakhir, dunia kedirgantaraan Indonesia mengalami kemajuan yang cukup pesat khususnya pada teknologi pesawat tanpa awak. Pesawat tanpa awak atau yang sering disebut sebagai Unmanned Aerial Vehicle (UAV) merupakan sebuah wahana yang dapat terbang tanpa adanya awak atau pilot. Dalam pengoperasiannya, pesawat tanpa awak dikendalikan langsung oleh operator melalui jaringan komunikasi tertentu seperti remote control atau secara otomatis melalui perangkat yang telah ditanamkan program sebelumnya.

Penelitian dan pengembangan sistem UAV sangat luas, apabila dikategorikan akan menjadi beberapa sub bagian seperti air vehicle, ground control station, payloads, data link dan support equipment [1]. Dalam operasional UAV, tugas ground control station sebagai stasiun pemantauan dan komando sehingga operator di darat dapat mengirimkan perintah misi, mengawasi jalannya misi tersebut dan memantau kondisi UAV selama misi berlangsung . Ground control station (GCS) dalam melakukan pemantauan kondisi UAV bergantung pada kemampuan komunikasi antara GCS dengan UAV.

Pada penelitian sebelumnya yang telah dilakukan[2,3], ground control station dapat melakukan pemantauan kondisi UAV pada jarak terbatas. Hal ini dikarenakan komunikasi antara GCS dengan UAV memanfaatkan jaringan lokal. Sehingga area cakupannya menjadi terbatas dan GCS tidak dapat diakses oleh operator yang berada di luar area jaringan lokal. Ground control station yang hanya bisa memantau kondisi dan mengendalikan UAV pada jarak terbatas saja tentunya tidak baik, karena untuk melakukan pengawasan diperlukan ground control station yang dapat memberikan pantauan kondisi dan kendali UAV secara terus menerus.

Sehingga diperlukan sistem ground control station yang mampu terhubung dengan UAV tanpa terbatas dengan jangkauan pemancar kendali. Dengan sistem ini di harapkan dapat memberikan kemudahan dalam pengoperasion pesawat tanpa awak.

\section{METODE PENELITIAN}

\subsection{Analisis Kebutuhan}

Salah satu kebutuhan pesawat tanpa adalah stasiun pemantauan. Stasiun pemantauan tersebut digunakan untuk memantau keadaan sekitar saat pesawat tanpa awak beroperasi. Untuk itu dibutuhkan suatu sistem stasiun pemantauan yang memenuhi spesifikasi sebagai berikut:

- Panel instrumen penerbangan yang dapat menampilkan keadaan UAV untuk mempermudah pengamatan.

- Panel peta penerbangan yang menampilkan posisi UAV saat penerbangan.

- Panel tampilan visual yang menampilkan keadaan sekitar UAV.

- Penampil data kondisi pesawat pada saat UAV beroperasi.

- Fungsi perintah kendali yang dapat mengendalikan UAV.

\section{2 Deskripsi Sistem}

Rancangan keseluruhan sistem dibagi menjadi dua bagian, yaitu rancangan unit terbang dan rancangan unit GCS yang ditunjukkan pada Gambar 1. Unit terbang merupakan unit yang terdapat pada pesawat tanpa awak terdiri dari ADAHRS (Air Data/ Attitude/ Heading Reference System) sebagai penyedia data sensor[4], webcam digunakan untuk merekam tampilan visual keadaan UAV, SBC (single board computer) Raspberry Pi sebagai unit pemroses dan modem sebagai modul penghubung ke unit GCS melalui jaringan internet. Modul ADAHRS memiliki fungsi mendeteksi kecepatan laju, ketinggian, posisi dan sikap UAV dengan sensor yang sudah terintegrasi. Raspberry Pi akan menerima data dari modul ADAHRS dan webcam, lalu mengirimkan data tersebut ke unit GCS melalui jaringan internet dengan modem. Unit GCS

IJEIS Vol. 8, No. 1, April 2018: $1-12$ 
mampu menerima dan menginterpretasikan data dari unit terbang pada antarmuka aplikasi. Paket data diterima, dimasukan dalam database, kemudian dilakukan parsing data dan didistribusikan ke setiap panel antarmuka yang membutuhkan.

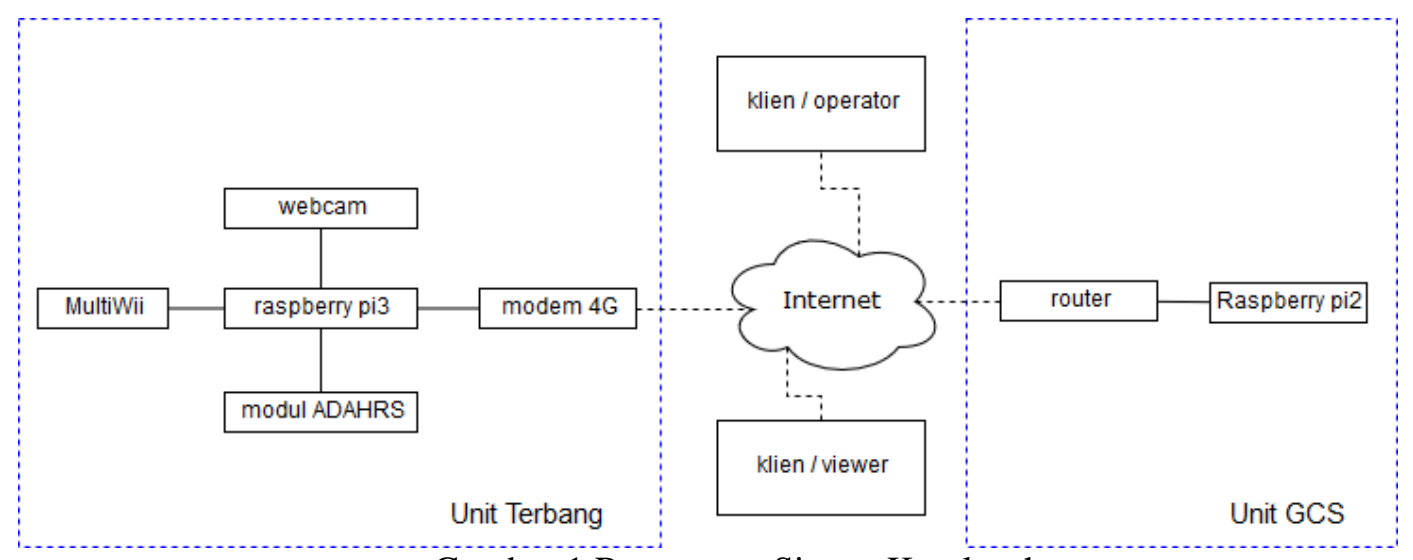

Gambar 1 Rancangan Sistem Keseluruhan

Proses awal agar kedua unit bisa saling terhubung dengan cara membuat sambungan socket anatar kedua unit. Seperti yang ditunjukkan pada Gambar 2, pada unit GCS diawali dengan membuat socket, kemudian mengikat socket pada ip lokal unit GCS. Setelah itu mendengarkan sambungan dari unit terbang, ketika mendeteksi adanya sambungan socket dari unit terbang kemudian membaca kiriman data ADAHRS dan di-update pada database. Kemudian unit GCS mengirimkan database kendali ke unit terbang. Proses ini secara rutin berulang selama ada data yang diterima dari unit terbang.
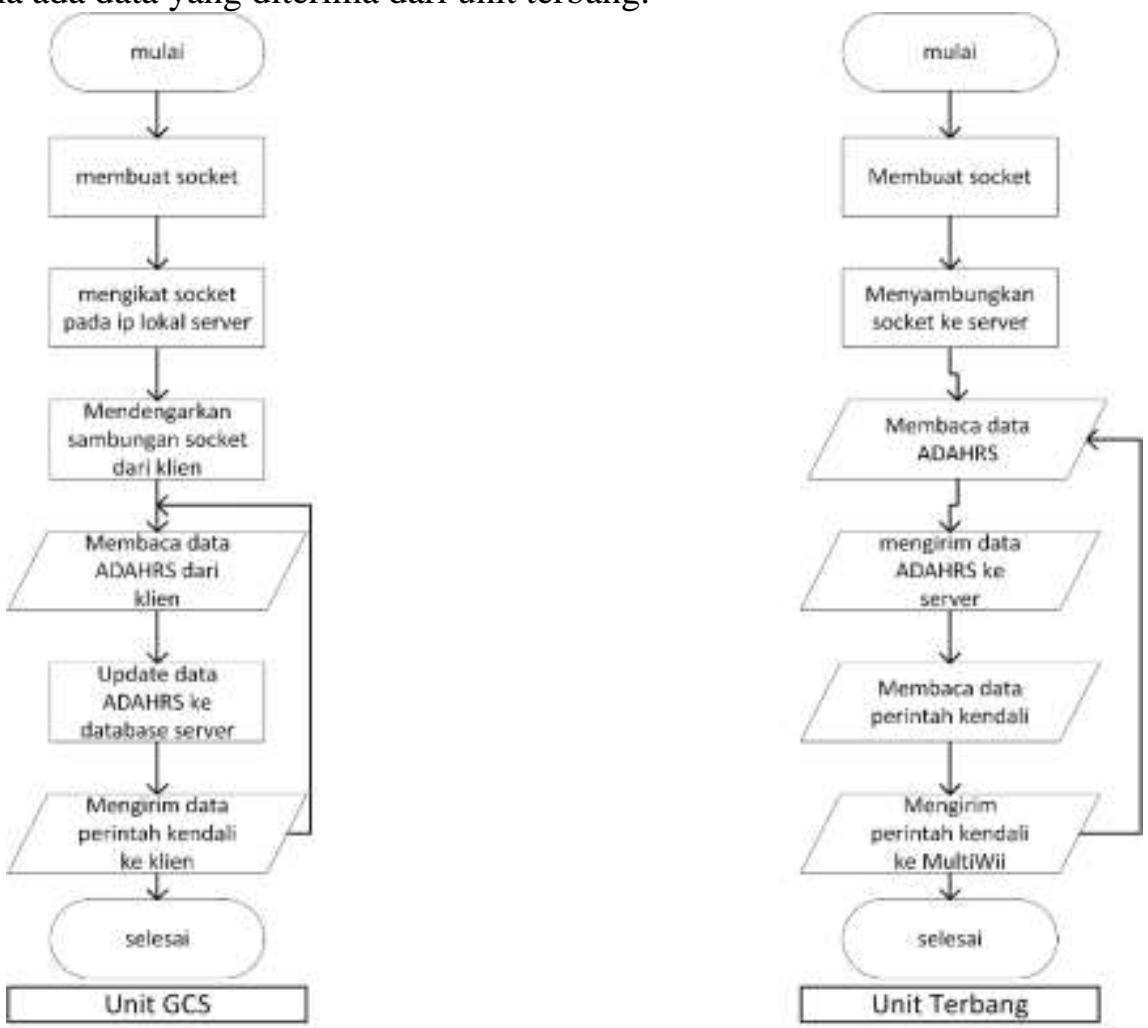

Gambar 2 Diagram alir komunikasi socket unit GCS dan unit terbang

Proses alir komunikasi data pada unit terbang di mulai dengan membuat socket kemudian melakukan sambungan ke unit GCS. Setelah berhasil, raspberry pi membaca data dari 
modul ADAHRS yang berisikan kondisi UAV. Kemudian data ini dikirimkan ke unit GCS, setelah data terkirim akan menerima respon berupa kiriman data kendali dari unit GCS. Data kendali tersebut kemudian dikirimkan ke MultiWii.

\section{3 Rancangan Perangkat Keras}

Perangkat keras pada sistem ini terbagi atas 2 bagian, yaitu perangkat keras pada unit terbang dan unit GCS.

\section{3.1 Rancangan Perangkat Keras Unit Terbang}

Pada pesawat tanpa awak akan dipasangi perangkat keras, antara lain modul ADAHRS, webcam, Raspberry Pi3 dan modem. Modul ADAHRS ini memiliki dua sensor yang digunakan untuk menentukan sikap pesasawat, yaitu GPS (Global Positioning Unit), IMU (Inertial Moment Unit). GPS berfungsi sebagai pendeteksi ketinggian, kecepatan dan lokasi UAV berdasarkan lokasi geologis yang mengacu pada garis lintang dan garis bujur bumi. IMU memiliki fungsi untuk mendeteksi ketinggian, kecepatan dan rotasi posisi UAV terhadap sumbu $\mathrm{x}, \mathrm{y}, \mathrm{z}$ yang diinterpretasikan sebagai sudut $\mathrm{roll} / \mathrm{miring}$, pitch/mengangguk dan $\mathrm{yaw} / \mathrm{menoleh}$.

Webcam digunakan sebagai masukan video streaming. Webcam yang digunakan memiliki resolusi 5 MP dan mampu mengolah video dengan kemampuan maksimal 30 framepersecond (fps). Selanjutnya Webcam tersebut dihubungkan pada Raspberry Pi dengan menggunakan koneksi USB. Raspberry Pi digunakan sebagai pengolah data video streaming yang didapatkan dari Webcam[5]. Kemudian mengirimkan data video streaming tersebut ke server melalui jaringan internet. Agar sistem dapat terkoneksi ke internet, maka digunakan modem yang dipasang pada Raspberry Pi.

Sistem pengiriman perintah kendali dari GCS ke UAV juga dilakukan menggunakan komunikasi jalur internet. Ketika mode kendali aktif, setiap kali klien melakukan kendali akan mengubah database kendali pada server, dan unit terbang akan memperbaharui datanya berdasarkan database kendali pada server[6]. Database kendali ini menjadi acuan bagi unit terbang untuk melakukan tanggapan.

\section{3.2 Rancangan Perangkat Keras Unit GCS}

Pada unit GCS terdiri atas Raspberry pi2 yang dijadikan sebagai server. Raspberry pi tersebut di hubungkan dengan router agar mendapatkan koneksi internet dari ISP. Untuk ISP menggunakan layanan INDIHOME dengan kecepatan download $10 \mathrm{Mbps}$ dan upload $1.5 \mathrm{Mbps}$.

\section{4 Rancangan Perangkat Lunak}

Pada rancangan perangkat lunak juga di bagi menjadi 2 bagian utama, yaitu perangkat lunak pada unit terbang dan perangkat lunak pada unit GCS.

\section{4.1 Rancangan Perangkat Lunak Unit Terbang}

Rancangan perangkat lunak pada unit terbang dibagi menjadi tiga macam fungsi utama, yaitu perangkat lunak yang digunakan untuk mengirimkan data penerbangan (kondisi dan sikap pesawat) dari UAV ke GCS, pengiriman data video streaming dari webcam yang terpasang pada UAV ke GCS dan yang terakhir mode penerimaan data perintah kendali UAV dari GCS.

Pengiriman data penerbangan berupa paket data ADAHRS yang telah diproses oleh Raspberry Pi kemudian dikirim ke server melalui jaringan internet. Proses pengiriman data dari ADAHRS ke Raspberry menggunakan komunikasi serial, sedangkan proses pengiriman paket data ADAHRS dari Raspberry ke server GCS menggunakan protokol TCP (Transmission Control Protocol)[7]. Paket data tersebut nantinya tersimpan dalam database mySQL pada server untuk ditampilkan pada antarmuka ground control station.

Untuk melakukan pengiriman data video streaming ke server di gunakan program framework FFMPEG[8]. Penggunaan program agar dapat terhubung dengan server dengan cara menambahkan alamat ip public server[9].

IJEIS Vol. 8, No. 1, April 2018: $1-12$ 


\section{4.1 Rancangan Perangkat Lunak Unit GCS}

Pada unit GCS agar dapat berperan sebagai server maka di berikan program Apache dan MySQL untuk pengelolaan database. Untuk penerimaan data video dari unit terbang dengan menjalankan program FFServer. FFServer merupakan bagian dari program FFMPEG yang berfungsi sebagai penerima data video streaming.

Untuk penerimaan data ADAHRS dan pengiriman data kendali dilakukan dengan menggunakan socket programming. Unit GCS akan menerima data ADAHRS dan mengirimkan data kendali melalui pemrograman socket. Data ADAHRS yang di terima disimpan pada database MySQL[10]. Dan unit GCS akan mengirimkan data kendali dengan mengambil data dari database kendali MySQL.

\section{5 Rancangan Protokol Kendali dan Video Straming}

Pada mode penerimaan perintah kendali seperti ditunjukkan Gambar 3, dapat digunakan ketika sudah diaktifkan dengan cara memasukkan user dan password pada landing page GCS. Setelah berhasil login, mode kendali pada antarmuka GCS sudah aktif. Apabila operator menekan tombol tertentu pada keyboard akan mengubah database kendali yang akan membuat unit terbang melakukan tanggapan aksi. Raspberry mengambil database kendali pada server menggunakan socket programming pada port khusus.

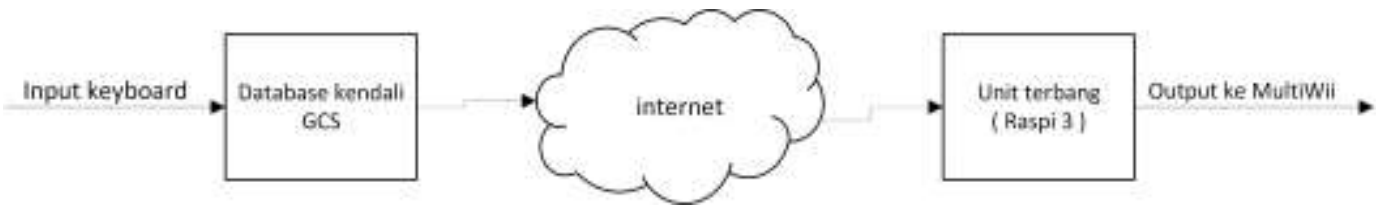

Gambar 3 Diagram fungsi kendali

Untuk proses video streaming digunakan protocol http, hal ini dikarenakan program FFServer dapat berjalan dengan menerima data yang menggunakan protocol http. Untuk mengakses video streaming dengan mengakses alamat ip dan port yang sudah ditentukan untuk proses penampilan video streaming. Untuk diagram proses video streaming seperti pada Gambar 4.

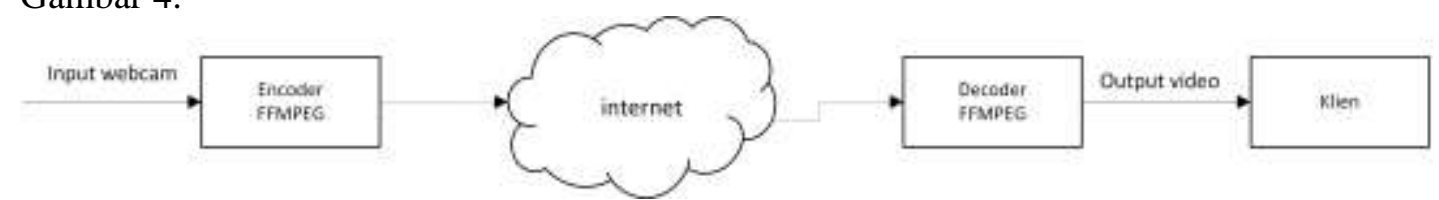

Gambar 4 Diagram proses video streaming

\section{6 Rancangan Antarmuka GCS}

Rancangan tampilan antarmuka pada ground control station ditunjukkan oleh Gambar 5. Antarmuka ini memiliki 3 panel utama yaitu panel flight instrument dan data ADAHRS, panel peta penerbangan dan panel penampil video streaming. Panel flight instrument, data ADAHRS, panel peta penerbangan mendapatkan data dari mengakses database mySQL yang ter-update data ADAHRS. Panel video streaming mendengarkan IP public server dengan port yang ditentukan sebelumnya.

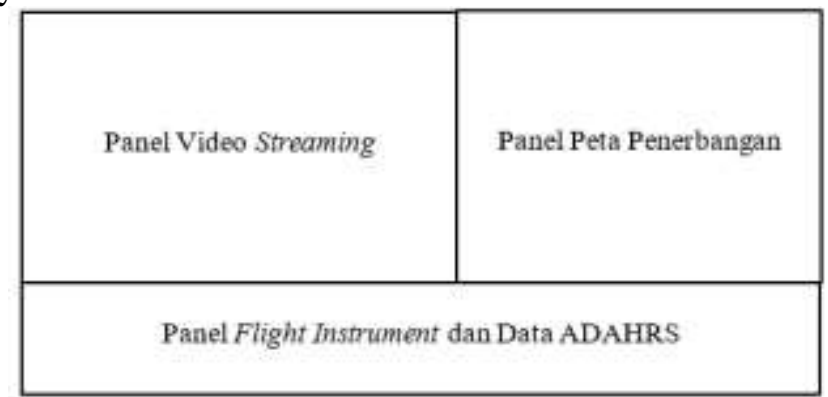

Gambar 5 Rancangan Antarmuka Ground Control Station 


\section{HASIL DAN PEMBAHASAN}

\subsection{Hasil Pengujian RTT, Download dan Upload dengan ISP yang berbeda}

Pengujian ini dilakukan untuk mengetahui ISP mana yang memiliki hasil paling stabil untuk digunakan. Pengujian dengan tiga ISP yang berbeda yaitu B, C dan A. Parameter yang diujikan antara lain RTT, kecepatan download/upload pada jaringan 4G maupun 3G. Setiap parameter dilakukan pengambilan data minimal 10 kali dan lokasi pengujian dilakukan pada koordinat latitude -7.7576599 dan longitude 110.3719617. Pengujian dilakukan dengan jeda setiap 5 menit untuk masing - masing ISP.

RTT ( round-trip time ) adalah waktu yang diperlukan untuk sebuah sinyal dari pengirim sampai ke penerima dan kembali lagi ke pengirim, sehingga semakin kecil nilai RTT akan semakin baik. Untuk mengetahui nilai RTT dilakukan dengan uji ping.

Tabel 1 Rata - rata nilai ping, download dan upload pada 3 ISP

\begin{tabular}{|c|c|c|c|c|c|c|}
\hline \multirow{2}{*}{ ISP } & \multicolumn{3}{|c|}{$3 \mathrm{G}$} & \multicolumn{3}{c|}{$4 \mathrm{G}$} \\
\cline { 2 - 7 } & Ping $(\mathrm{ms})$ & Download & Upload & Ping $(\mathrm{ms})$ & Download & Upload \\
\hline $\mathrm{A}$ & 71,14 & $1,5 \mathrm{Mbps}$ & $2,94 \mathrm{Mbps}$ & 40,11 & $1,48 \mathrm{Mbps}$ & $9,45 \mathrm{Mbps}$ \\
\hline $\mathrm{B}$ & 219,98 & $0,58 \mathrm{Mbps}$ & $0,7 \mathrm{Mbps}$ & 66,86 & $0,92 \mathrm{Mbps}$ & $0,94 \mathrm{Mbps}$ \\
\hline C & 96,24 & $1,21 \mathrm{Mbps}$ & $1,39 \mathrm{Mbps}$ & 63,93 & $1,53 \mathrm{Mbps}$ & $8,75 \mathrm{Mbps}$ \\
\hline
\end{tabular}

Dari Tabel 1 didapatkan hasil jika ISP A memiliki hasil paling stabil pada kedua jaringan, sehingga akan digunakan untuk pengujian selanjutnya.

\subsection{Hasil Pengujian Pengiriman Data Kondisi Pesawat}

Pengujian pengiriman data kondisi pesawat dilakukan antara unit terbang dan unit GCS yang saling terhubung. Pengiriman data melalui socket menggunakan protocol TCP. Protokol ini memiliki kelebihan yaitu pada proses pembuatan koneksi TCP yang biasa disebut three way handshake.

Proses ini dengan cara host pertama mengirimkan sinyal kepada host kedua. jika diterima, host kedua mengirimkan sinyal balik kepada host pertama. Apabila sinyal tersebut diterima host pertama, pertukaran data kemudian berlangsung. Proses ini juga berlangsung pada saat mengakhiri koneksi yang dibuat. Sehingga menjamin data yang dikirim diterima dengan baik.

Pengujian pengiriman paket data ini menggunakan modul ADAHRS yang di program untuk mengeluarkan data penerbangan melalui serial port USB. Kemudian disambungkan ke raspberry pi pada unit terbang dan dilakukan pengiriman data melalui socket ke unit GCS. Pengujian ini dimaksudkan untuk menguji kemampuan GCS dalam menerima paket data yang dikirim unit terbang.

Pengujian dilakukan pada beberapa lokasi area yang berbeda. Pengujian pertama pada area berjaringan 4G dengan koordinat Lat : -7.75761 dan Long : 110.37200 atau area pemukiman padat penduduk. Untuk ping 40,11 ms, kecepetan download 1,48Mbps dan upload 9,45Mbps.

Tabel 2 Hasil pengiriman paket data ADAHR pada area padat penduduk

\begin{tabular}{|c|c|c|c|c|c|c|}
\hline No & Dikirim & Diterima & Waktu(s) & Paket/dtk & Sukses & Loss \\
\hline 1 & 182 & 180 & 10,4 & 17 & $98,90 \%$ & $1,10 \%$ \\
\hline 2 & 182 & 179 & 10,4 & 17 & $98,35 \%$ & $1,65 \%$ \\
\hline 3 & 178 & 177 & 10,3 & 17 & $99,44 \%$ & $0,56 \%$ \\
\hline 4 & 180 & 179 & 10,4 & 17 & $99,44 \%$ & $0,56 \%$ \\
\hline 5 & 184 & 183 & 10,5 & 17 & $99,46 \%$ & $0,54 \%$ \\
\hline \multicolumn{7}{|c|}{ Rata - rata } \\
\hline
\end{tabular}

Tampak pada Tabel 2, GCS rata - rata menerima sebanyak 17 paket data per detik. Untuk tingkat keberhasilan data yang dapat diterima secara utuh pada sistem ges rata - rata 99,12\%.

Pada pengujian kedua dilakukan pada area berjaringan 4G dengan koordinat Lat : 7.77130 | Long : 110.37688 atau di Graha Sabha Pramana UGM. Untuk hasil ping pada lokasi tersebut sebesar 43,12 ms, download 1,48 Mbps dan upload 6,98 Mbps. Dari Tabel 3 dapat 
dilihat rata - rata paket ADAHRS yang terkirim 16 paket data per detik dengan prosentase keberhasilan diterima sebesar 98,95\%.

Tabel 3 Hasil pengiriman paket data ADAHR pada area GSP UGM

\begin{tabular}{|c|c|c|c|c|c|c|}
\hline No & Dikirim & Diterima & Waktu(s) & Paket/dtk & Sukses & Loss \\
\hline 1 & 167 & 164 & 10,2 & 16 & $98,20 \%$ & $1,80 \%$ \\
\hline 2 & 169 & 169 & 10,4 & 16 & $100 \%$ & $0,00 \%$ \\
\hline 3 & 174 & 172 & 10,5 & 16 & $98,85 \%$ & $1,15 \%$ \\
\hline 4 & 170 & 169 & 10,5 & 16 & $99,41 \%$ & $0,59 \%$ \\
\hline 5 & 174 & 171 & 10,6 & 16 & $98,28 \%$ & $1,72 \%$ \\
\hline \multicolumn{7}{|c|}{ Rata - rata } \\
\hline
\end{tabular}

Pada pengujian ketiga dilakukan pada area berjaringan 3G dengan koordinat Lat : 7.70121 | Long : 110.79819 atau di area pedesaan. Untuk hasil ping pada lokasi tersebut sebesar 47,74 ms, download 1,3 Mbps dan upload 1,1 Mbps. Rata - rata paket ADAHRS yang terkirim 16 paket data per detik dengan prosentase keberhasilan diterima sebesar $98,10 \%$ seperti pada Tabel 4.

Tabel 4 Hasil pengiriman paket data ADAHR pada area pedesaan

\begin{tabular}{|c|c|c|c|c|c|c|}
\hline No & Dikirim & Diterima & Waktu(s) & Paket/dtk & Sukses & Loss \\
\hline 1 & 161 & 157 & 10,5 & 15 & $97,52 \%$ & $2,48 \%$ \\
\hline 2 & 155 & 152 & 10,6 & 14 & $98,06 \%$ & $1,94 \%$ \\
\hline 3 & 157 & 155 & 10,5 & 15 & $98,73 \%$ & $1,27 \%$ \\
\hline 4 & 123 & 120 & 10,2 & 12 & $97,56 \%$ & $2,44 \%$ \\
\hline 5 & 147 & 145 & 10,5 & 14 & $98,64 \%$ & $1,36 \%$ \\
\hline \multicolumn{7}{|c|}{ Rata - rata } \\
\hline
\end{tabular}

Rata - rata jumlah paket data yang dapat diterima secara utuh oleh GCS dari ketiga lokasi pengujian sebesar 16 paket per detik. Tiap 1 paket memiliki ukuran sebesar 60 byte, sehingga dalam satu detik dihasilkan data sebesar 7680 bit atau 7,68 Kbps. Data kondisi pesawat yang dikirim ke GCS optimal apabila bandwidth internet (upload) melebihi bitrate video streaming sebesar 7,68 Kbps.

Adanya perbedaan jumlah data yang terkirim dengan yang diterima karena pada program socket penerima melakukan filtering. Apabila jumlah data yang di pecah tidak sejumlah 9 data, data tidak akan dimasukkan ke dalam database. Hal ini dikarenakan awal pengiriman data serial dari modul ADAHRS ke raspberry pada unit terbang ada data yang tidak sempurna/utuh. Terlihat pada Gambar 5 pada awal paket data terjadi error.

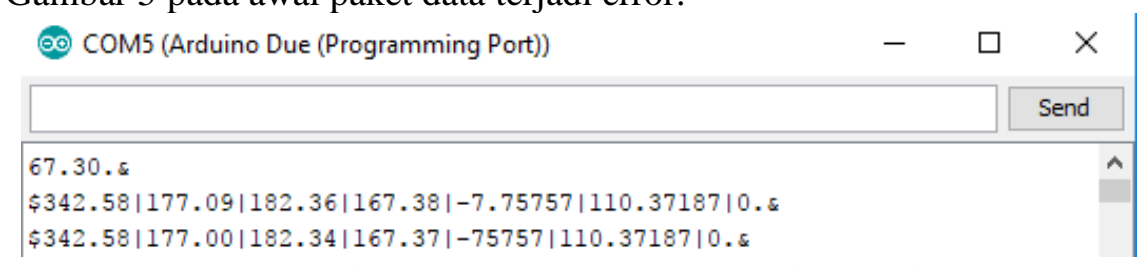

Gambar 5 Tampilan data ADAHRS pada Serial Monitor

Hal ini dikarenakan komunikasi serial merupakan transmisi asynchronous. Pada transmisi ini, sebelum terjadi komunikasi tidak diadakan sinkronisasi clock antara pengirim dan penerima. Sehingga sering terjadi kehilangan data pada awal pengiriman.

\subsection{Hasil Pengujian Video Streaming}

Pengujian video streaming dilakukan untuk mengetahui konfigurasi optimum untuk panel video streaming pada sistem GCS. Pengujian dengan melakukan proses video streaming pada beberapa lokasi. Dalam pengujian ini sebagai acuan adalah delay time pada video streaming yang tidak lebih dari satu detik.

Karena delay time yang ingin dicapai tidak lebih dari satu detik atau kita anggap satu detik, maka yang menentukan adalah kecepatan upload jaringan dari unit terbang ke unit GCS. Semisal kecepatan upload 10Mbps, bitrate video streaming tidak boleh melebihi kecepatan upload. Untuk perhitungan ditunjukkan pada Rumus 1 
Video bitrate $=$ resolusi $\mathrm{x}$ kedalaman warna $\mathrm{x}$ framerate

Webcam yang digunakan memiliki kedalaman warna true color. True color berarti memiliki warna RGB. Tingkat kedalaman warna pada RGB adalah 1 byte ( 8 bit) untuk setiap komponen warnanya. Karena RGB terdiri dari 3 komponen warna (RED, GREEN, BLUE), nilai RGB untuk satu pixel sebesar 3 byte atau 24 bit. Dari Rumus 6.1 dapat dihitung bitrate untuk resolusi 320x240 pixel dan framerate 5 fps yaitu sebesar 9,22 Mbps. Sehingga untuk kecepatan $10 \mathrm{Mbps}$, resolusi tersebut masih mampu untuk menghasilkan delay time tidak lebih dari satu detik.

Tabel 5 Hasil perhitungan bitrate video pada beberapa resolusi

\begin{tabular}{|c|c|c|c|}
\hline Resolusi (pixel) & Kedalaman warna & Framerate & Bitrate \\
\hline $240 \times 144$ & 24 bit & $5 \mathrm{fps}$ & $4,15 \mathrm{Mbps}$ \\
\hline $320 \times 240$ & $24 \mathrm{bit}$ & $5 \mathrm{fps}$ & $9,22 \mathrm{Mbps}$ \\
\hline $640 \times 480$ & $24 \mathrm{bit}$ & $5 \mathrm{fps}$ & $36,86 \mathrm{Mbps}$ \\
\hline $800 \times 600$ & $24 \mathrm{bit}$ & $5 \mathrm{fps}$ & $57,6 \mathrm{Mbps}$ \\
\hline $1024 \times 600$ & $24 \mathrm{bit}$ & $5 \mathrm{fps}$ & $73,73 \mathrm{Mbps}$ \\
\hline
\end{tabular}

Pada Tabel 5 dapat dilihat bahwa semakin besar resolusi semakin besar pula bitrate yang dihasilkan. Semakin besar bitrate semakin baik pula kualitas video yang dihasilkan. Namun dengan bitrate yang semakin besar, kebutuhan bandwidth jaringan juga semakin besar. Oleh karena itu diperlukan kompresi dalam proses video streaming.

Pada pengujian video streaming ini dilakukan pada tiga lokasi yang berbeda, pengujian pertama pada area berjaringan 4G dengan koordinat Lat : -7.75761 dan Long : 110.37200 atau area pemukiman padat penduduk. Pada lokasi pengujian ini memiliki nilai ping 40,11 ms dan kecepatan upload sebesar 9,45Mbps. Pengujian dilakukan dengan memvariasi resolusi, sedangkan bitrate maksimum dikonfigurasi pada nilai 1024kbps.

Untuk hasil delay time rata-rata pada resolusi 1024x600 5,13 detik, resolusi 800x600 3,77 detik, resolusi 640x480 2.55 detik dan resolusi 320x240 0,51 detik. Sedangkan untuk framerate semua menghasilkan $5 \mathrm{fps}$. Lebih lengkapnya dapat dilihat pada Tabel 6.

Tabel 6 Data hasil kompresi video streaming pada area padat penduduk

\begin{tabular}{|c|c|c|c|c|}
\hline Resolusi & Bitrate webcam & Bitrate maks & \% kompresi & Delay time \\
\hline $320 \times 240$ & $9,22 \mathrm{Mbps}$ & $1024 \mathrm{kbps}$ & $88,89 \%$ & $0,51 \mathrm{~s}$ \\
\hline $640 \times 480$ & $36,86 \mathrm{Mbps}$ & $1024 \mathrm{kbps}$ & $97,22 \%$ & $2,55 \mathrm{~s}$ \\
\hline $800 \times 600$ & $57,6 \mathrm{Mbps}$ & $1024 \mathrm{kbps}$ & $98,22 \%$ & $3,77 \mathrm{~s}$ \\
\hline $1024 \times 600$ & $73,73 \mathrm{Mbps}$ & $1024 \mathrm{kbps}$ & $98,61 \%$ & $5,13 \mathrm{~s}$ \\
\hline
\end{tabular}

Dapat dilihat bahwa resolusi mempengaruhi besarnya kompresi yang dilakukan serta berimbas pada hasil delay time video streaming. Semakin besar resolusi video streaming maka semakin besar delay time yang dihasilkan. Hal ini dikarenakan encoder dalam memproses/mengkompresi data yang lebih besar akan membutuhkan waktu lebih lama, sehingga menyebabkan delay time bertambah.

Pada pengujian kedua dilakukan pada area berjaringan 4G dengan koordinat Lat : 7.77130 | Long : 110.37688 atau di Graha Sabha Pramana UGM. Untuk pengujian dilakukan dengan resolusi 320x240 saja. Untuk hasil ping pada lokasi ini sebesar 43,12 ms dan upload 6,98 Mbps. Untuk delay time video streaming dengan maksimal bitrate 1024kbps rata - rata 1,8 detik dan framerate 5 fps. Karena delay time masih lebih dari satu detik, dicoba video streaming dengan maksimal bitrate 256kbps. Pada pengujian bitrate maksimal 256kbps ini didapatkan delay time rata - rata sebesar 0,8 detik dan framerate $5 \mathrm{fps}$.

Tabel 7 Data hasil kompresi video streaming pada area GSP

\begin{tabular}{|c|c|c|c|c|}
\hline Resolusi & Bitrate webcam & Bitrate maks & \% kompresi & Delay time \\
\hline $320 \times 240$ & $9,22 \mathrm{Mbps}$ & $1024 \mathrm{kbps}$ & $88,89 \%$ & $1,8 \mathrm{~s}$ \\
\hline $320 \times 240$ & $9,22 \mathrm{Mbps}$ & $256 \mathrm{kbps}$ & $97,22 \%$ & $0,8 \mathrm{~s}$ \\
\hline
\end{tabular}

Bitrate maksimal merupakan banyaknya data dalam satuan bit yang dapat diproses oleh encoder dalam satu detik. Semakin tinggi nilai bitrate video akan membuat semakin banyak

IJEIS Vol. 8, No. 1, April 2018 : 1 - 12 
data yang diproses, berimbas pada delay time video streaming. Semakin rendah nilai bitrate juga akan menurunkan kualitas video streaming. Terlihat pada Tabel 7 pada resolusi 320x240 dengan bitrate maksimal diturunkan menjadi 256kbps membuat prosentase kompresi meningkat menjadi $97,22 \%$. Meskipun prosentrase kompresi meningkat, tetapi dapat menurunkan delay time video streaming menjadi tidak lebih dari satu detik.

Pada pengujian ketiga dilakukan pada area berjaringan 3G dengan koordinat Lat : 7.70121 | Long : 110.79819 atau di area pedesaan. Pada lokasi ini memiliki nilai ping 47,74 ms dan kecepatan upload 1,1Mbps. Dengan kecepatan upload tersebut, dilakukan pengujian dengan resolusi 320x240 pixel dengan maksimal bitrate 1024kbps. Dari hasil pengujian didapatkan hasil delay time video streaming rata - rata 2,5 detik dan framerate 5 fps. Kemudian dilakukan lagi pengujian dengan bitrate maksimal 256kbps, didapatkan delay time rata - rata sebesar 2,11 detik dan framerate $5 \mathrm{fps}$.

Karena delay time masih lebih dari satu detik, dilakukan pengujian lagi dengan menurunkan resolusi dan bitrate maksimal video. Resolusi yang digunakan 240x144 pixel dan bitrate maksimal 256kbps. Dari pengujian ini didapatkan delay time rata - rata sebesar 0,84 detik dan framerate 5 fps.

Tabel 8 Data hasil kompresi video streaming pada area pedesaan

\begin{tabular}{|c|c|c|c|c|}
\hline Resolusi & Bitrate webcam & Bitrate maks & \% kompresi & Delay time \\
\hline $320 \times 240$ & $9,22 \mathrm{Mbps}$ & $1024 \mathrm{kbps}$ & $88,89 \%$ & $2,5 \mathrm{~s}$ \\
\hline $320 \times 240$ & $9,22 \mathrm{Mbps}$ & $256 \mathrm{kbps}$ & $97,22 \%$ & $2,11 \mathrm{~s}$ \\
\hline $240 \times 144$ & $4,15 \mathrm{Mbps}$ & $256 \mathrm{kbps}$ & $93,83 \%$ & $0,84 \mathrm{~s}$ \\
\hline
\end{tabular}

Dari pengujian lokasi ketiga ini dapat dilihat mesikpun resolusi 240x144 memiliki bitrate asli sebesar 4,15 Mbps, masih mampu untuk menghasilkan delay time video streaming tidak lebih dari satu detik. Hal ini dikarenakan adanya kompresi video dengan mengkonfigurasi bitrate maksimal menjadi 256kbps. Tampak pada Tabel 8 prosentase kompresinya sebesar 93,83\%.

Pada pengujian lokasi kedua dan ketiga sama - sama dilakukan pengujian menggunakan resolusi 320x240 dengan bitrate maksimal 256kbps. Akan tetapi menghasilkan delay time video streaming yang berbeda. Hal ini dikarenakan pada lokasi kedua memiliki kecepatan upload $6,98 \mathrm{Mbps}$ dan lokasi ketiga 1,1Mbps. Perbedaan kecepatan upload inilah yang menyebabkan delay time yang berbeda. Sehingga didapatkan konfigurasi optimum video streaming dengan menggunakan resolusi 240x144 pixel dan bitrate maksimal 256kbps pada area dengan kecepatan upload $1,1 \mathrm{Mbps}$.

\subsection{Hasil Pengujian Fungsi Kendali}

Pengujian ini dilakukan untuk mengetahui apakah data yang dikirimkan ke unit terbang sampai dan dapat dijalankan oleh MultiWii. Pengujian dengan menekan tombol L,J,K,H,G dan $\mathrm{V}$ pada keyboard dan melihat database GCS pada database dataperintah. Ketika operator menekan tombol fungsi kendali akan dibaca nilai ASCII tombol dan di update pada database kendali. Database kendali ini secara rutin dikirimkan GCS ke unit terbang.

Tabel 9 Data rcCMD yang dikirim ke MultiWii

\begin{tabular}{|l|c|c|c|}
\hline Tombol & Nilai throttle pada GCS & Prosentase \% trhottle & RPM Motor \\
\hline L ditekan & 710 & $90 \%$ & 10508 \\
\hline K ditekan & 610 & $78 \%$ & 10049 \\
\hline J ditekan & 510 & $67 \%$ & 9877 \\
\hline H ditekan & 410 & $55 \%$ & 9309 \\
\hline G ditekan & 310 & $43 \%$ & 8731 \\
\hline V ditekan & 210 & $31 \%$ & 7029 \\
\hline
\end{tabular}

Pada Tabel 9 menunjukkan data dari GCS sampai pada unit terbang dan menggerakkan motor pada quadrotor. Data rcCMD dikirimkan ke MultiWii apabila nilai throttle pada GCS lebih dari 200. 


\subsection{Hasil Pengujian Pemantauan Lebih Dari Satu Pengguna}

Pengujian ini dilakukan untuk mengetahui GCS dapat dipantau lebih dari satu pengguna dalam waktu yang bersamaan. Seperti pada Gambar 6, GCS dapat di akses oleh dua klien secara bersamaan.

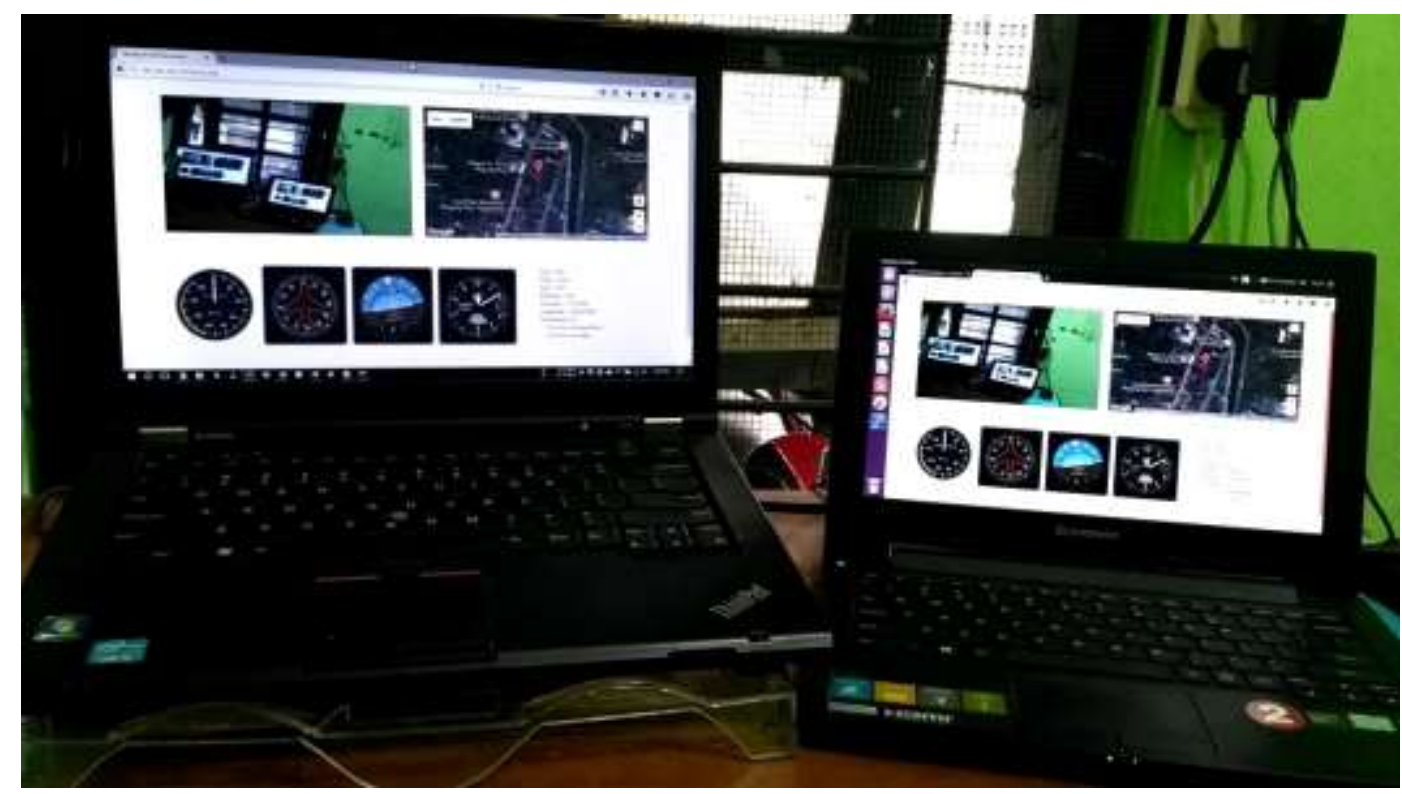

Gambar 6 GCS diakses bersamaan oleh dua client

Pada client sebelah kiri mengakses GCS melalui jaringan internet dengan mengakses ip public indihome yang di port forwarding ke ip server GCS. Sedangkan pada client sebelah kanan terhubung pada jaringan lokal server, sehingga untuk mengakses GCS melalui ip 192.168.100.5.

\subsection{Hasil pengujian keseluruhan sistem}

Pengujian keseluruhan sistem dengan cara menjalankan sistem GCS dengan melakukan penerbangan menggunakan pesawat tanpa awak bertipe quadrotor. Pengujian dilakukan pada lokasi dengan koordinat Lat : -7.75761 dan Long : 110.37200 atau area pemukiman padat penduduk. Pengujian dilakukan pukul 08.00 pagi. Pengujian penerbangan dilakukan untuk mengetahui kinerja keseluruhan sistem GCS.

Pada pengujian ini, ketinggian maksimal penerbangan didapatkan setinggi 5 meter. Untuk flight time sekitar 5 menit dari normal tanpa muatan unit terbang sekitar 15 menit. Hal ini dikarenakan unit terbang menambah massa pesawat tanpa awak, sehingga daya listrik yang digunakan untuk membuat quadrotor terbang semakin besar.

Untuk pengujian penerbangan dengan melakukan lepas landas pada quadrotor. Lepas landas dengan menekan tombol L yang memberikan nilai throttle sebesar 1768. Serta dilakukan pengamatan pada anatarmuka dan database GCS. Pada saat posisi UAV mulai naik, terlihat pada data altitude mengalami perubahan kenaikan ketinggian yang dapat dilihat pada Gambar 7.

IJEIS Vol. 8, No. 1, April 2018 : 1 - 12 


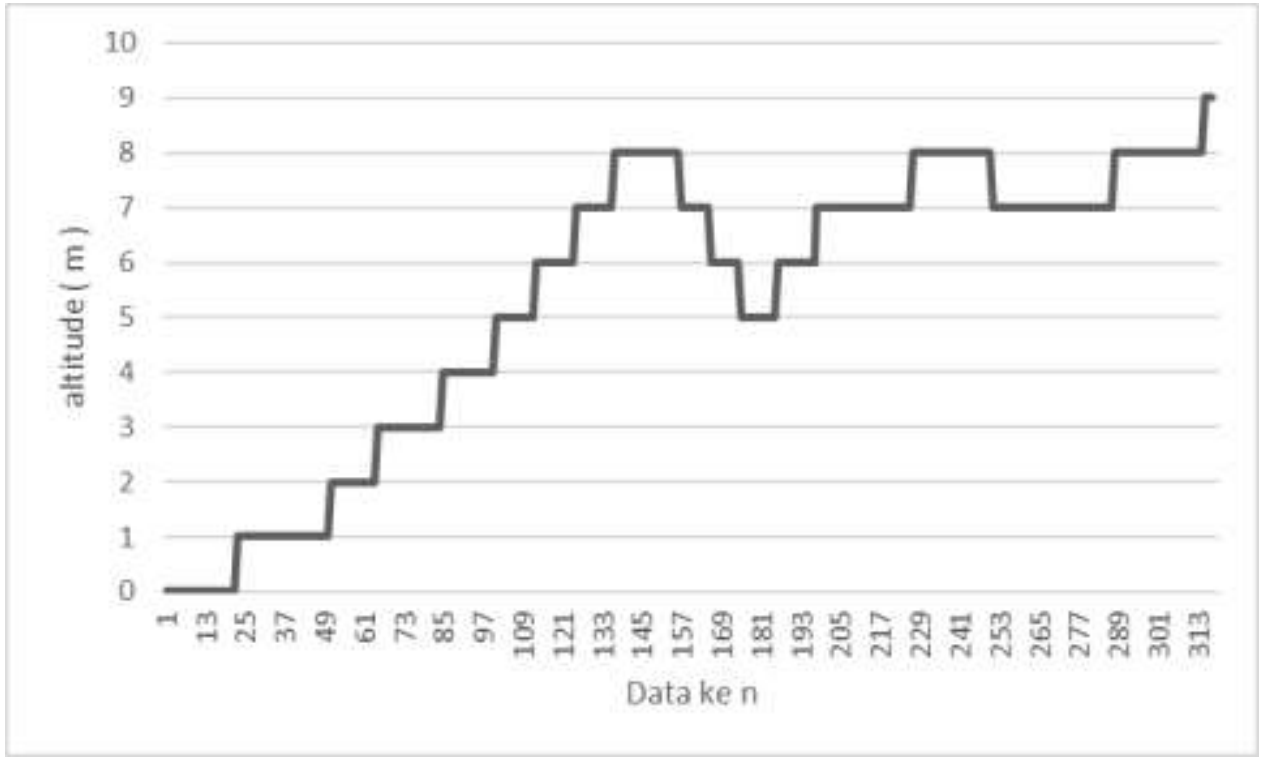

Gambar 7 Data perubahan altitude pada database

Gambar 7 menunjukkan adanya perubahan kenaikan ketinggian quadrotor dari 0 meter perlahan menuju 9 meter. Sehingga ketinggian terbang berdasarkan data altitude setinggi 9 meter, sedangkan dari pemantauan langsung dilapangan ketinggian maksimal quadrotor terbang sekitar 5 meter. Perbedaan ini dikarenakan modul gps yang digunakan memiliki nilai error dalam membaca ketinggian.

Tampilan video streaming dapat berjalan dengan lancar. Untuk panel peta penerbangan dapat menampilkan koordinat lokasi pesawat dengan jeda pembaharuan lokasi setiap empat detik.

\section{KESIMPULAN}

Penelitian ini berhasil mengimplementasikan sistem GCS berbasis internet web server yang dapat menampilkan kondisi pesawat, video streaming dan melakukan perintah kendali.

Konfigurasi video streaming dengan resolusi 240x144 pixel, bitrate maksimal 256kbps dan framerate $5 \mathrm{fps}$ menghasilkan delay time tidak lebih dari satu detik. Konfigurasi ini berjalan pada kecepatan upload 1.1 Mbps dengan prosentase kompresi bitrate 93.83\%. Data kondisi pesawat yang dikirim ke GCS optimal apabila bandwidth internet (upload) melebihi bitrate video streaming sebesar 7,68 Kbps.

\section{SARAN}

Dari penelitian ini, untuk pengembangan lebih lanjut dapat disarankan untuk pengujian terbang menggunakan pesawat yang memiliki daya angkat lebih tinggi dan daya baterai lebih besar agar flight time lebih lama. Menerapkan fungsi kendali perintah menggunakan joystick atau gamepad. Mencoba menggunakan framework selain FFMPEG agar diketahui apakah framework berpengaruh pada proses video streaming. 


\section{DAFTAR PUSTAKA}

[1] E. Torun, "UAV Requirements and Design Consideration," The Research and Technology Organization (RTO) of NATO, pp. B1-8, 2000 [Online]. Available: http://www.dtic.mil/get-tr-doc/pdf?AD=ADA381871\#page=222. [Accessed: 02-Jun2017]

[2] A. A. Farghani, R. Sumiharto, S. B. Wibowo, "Purwarupa Ground Control Station untuk Pengamatan dan Pengendalian Unmanned Aerial Vehicle Bersayap Tetap," IJEIS (Indonesian J. Electron. Instrum. Syst., vol. 3, no. 1, pp. 1-10, 2013 [Online]. Available: https://journal.ugm.ac.id/ijeis/article/view/3834. [Accessed: 02-Jun-2017]

[3] U. W. T. P. Putro, T. K. Priyambodo, and R. Sumiharto, "Pengembangan Antarmuka Stasiun Pemantauan Pesawat Tanpa Awak Menggunakan Aplikasi Android," IJEIS (Indonesian J. Electron. Instrum. Syst., vol. 4, no. 2, pp. 113-122, 2014 [Online]. Available: https://jurnal.ugm.ac.id/ijeis/article/view/7110. [Accessed: 01-Jun-2017]

[4] A. P. Manggala, R. Sumiharto, S. B. Wibowo, "Purwarupa Air Data, Attitude, dan Heading Reference System untuk Unmanned Aerial Vehicle," IJEIS (Indonesian J. Electron. Instrum. Syst., vol. 2, no. 1, pp. 21-32, 2012 [Online]. Available: https://jurnal.ugm.ac.id/ijeis/article/view/2337. [Accessed: 04-Jun-2017]

[5] E. N. Wijatsongko, A. E. Putra, B. N. Prastowo, "Sistem Pemantauan Ruangan Dengan Server Raspberry Pi," IJEIS (Indonesian J. Electron. Instrum. Syst., vol. 5, no. 1, pp. 6576, 2015 [Online]. Available: https://jurnal.ugm.ac.id/ijeis/article/view/7154. [Accessed: 04-Jun-2017]

[6] D. Holandrio, R. Sumiharto, B. A. A. Sumbodo, "Sistem Video Streaming dengan Server Mini Personal Computer (Mini Pc) pada Jaringan Ad-Hoc," IJEIS (Indonesian J. Electron. Instrum. Syst., vol. 2, no. 2, pp. 165-174, 2012 [Online]. Available: https://journal.ugm.ac.id/ijeis/article/view/2436. [Accessed: 02-Jul-2017]

[7] F. R. Hadiputra, T. K. Priyambodo, "Purwarupa Pengendalian Jarak Jauh Pada Mobile Robot Berbasis Web Melalui Jaringan Wireless TCP/IP," IJEIS (Indonesian J. Electron. Instrum. Syst., vol. 6, no. 1, pp. 105-116, 2016 [Online]. Available: https://jurnal.ugm.ac.id/ijeis/article/view/15247. [Accessed: 01-Jun-2017]

[8] Khan, A., Sun, L. and Ifeachor, E., 2009, June. Content clustering based video quality prediction model for MPEG4 video streaming over wireless networks. In Communications, 2009. ICC'09. IEEE International Conference on (pp. 1-5). Available: IEEE. http://ieeexplore.ieee.org/abstract/document/5198850/. [Accessed: 01-Jun-2017]

[9] S. S. Henura, T. W. Widodo, "Rancang Bangun Sistem Jaringan Nirkabel untuk Pemantauan Penggunaan Air Pelanggan PDAM," ," IJEIS (Indonesian J. Electron. Instrum. Syst., vol. 5, no. 2, pp. 155-164, 2015 [Online]. Available: https://jurnal.ugm.ac.id/ijeis/article/view/7639. [Accessed: 04-Jun-2017]

[10] I. F. Priyanta, M. Rivai, R. Dikairono, "Pemetaan Distribusi Gas Polutan Menggunakan Quadcopter Berbasis Autonomous Waypoint Navigation," Jurnal Teknik ITS, vol. 5 no. 2 2. 154-159, 2016 [online]. Available: http://ejurnal.its.ac.id/index.php/teknik/article/view/16238/0. [Accessed: 04-Jun-2017] 